Research Paper

\title{
Reduced Expression of TFFI and Increased Expression of TFF3 in Gastric Cancer: Correlation with Clinico- pathological Parameters and Prognosis
}

\author{
Soyoung Im, Changyoung Yoo, Ji-Han Jung ${ }^{\bowtie}$, Hyun Joo Choi, Jinyoung Yoo, Chang Suk Kang \\ Department of Hospital Pathology, St. Vincent's Hospital, College of Medicine, The Catholic University of Korea, Republic of Korea.
}

$\triangle$ Corresponding author: Ji-Han Jung, M.D., Ph.D. Department of Hospital Pathology, St. Vincent's Hospital, The Catholic University of Korea, 93, Ji-dong, Paldal-gu, Suwon 442-723, Republic of Korea. Tel: 82-31-249-7633, Fax: 82-31-244-6786, E-mail: apjjh225@catholic.ac.kr.

(c) Ivyspring International Publisher. This is an open-access article distributed under the terms of the Creative Commons License (http://creativecommons.org/ licenses/by-nc-nd/3.0/). Reproduction is permitted for personal, noncommercial use, provided that the article is in whole, unmodified, and properly cited.

Received: 2012.11.07; Accepted: 2012.12.26; Published: 2012.12.30

\begin{abstract}
Objectives: The trefoil factor family (TFF) is composed of three thermostable, and protease-resistant proteins, named TFFI, TFF2 and TFF3, and plays a role in gastrointestinal mucosal defence and repair. Recently, TFFs have been found to be related to the development of various types of cancer. This study assessed the relationship between the expression of TFFI and TFF3 and the clinicopathological parameters in gastric carcinoma (GC). Materials and Methods: The expression of TFFI and TFF3 was analyzed by immunohistochemistry in 292 GCs and 20 normal gastric tissues. Results: All normal gastric tissues expressed TFFI, but $53.8 \%$ of GCs showed reduced TFFI expression. However, TFF3 was not detected in normal gastric tissues and $44.2 \%$ of GCs showed a high level of expression. Highly expressed TFF3 was significantly correlated with lymph node metastasis, lymphatic invasion, vein invasion, and advanced stage. The overall survival was shorter in patients with high expression of TFF3 than in those with low expression of TFF3 in 292 GCs and in I 25 early GCs (EGCs). Moreover, in patients with EGCs, high expression of TFF3, associated with reduced expression of TFFI, was determined as an independent poor prognostic marker. Conclusions: Reduced expression of TFFI and increased expression of TFF3 may play a role in the carcinogenesis of gastric cancer. Furthermore, high expression of TFF3 with reduced expression of TFFI may be a marker of poor prognosis for patients with EGC.
\end{abstract}

Key words: TFF1, TFF3, gastric cancer

\section{Introduction}

Gastric cancer is the third most common cancer and is the second leading cause of cancer deaths worldwide [1]. In spite of advanced chemotherapy and radiotherapy, the only curative treatment for gastric cancer is surgical resection of primary tumors with appropriate lymphadenectomy since trials of neoadjuvant therapy have for the most part been disappointing [2]. Some patients with gastric cancer, even with the same TNM stage, have different prognoses and treatment responses. Therefore, recent molecular studies have provided a better understanding of the biology of gastric cancer and have identified multiple factors responsible for the modulation of tumor progression, invasion and metastasis formation.

Trefoil peptide family (TFF) domain peptides, characterized by the presence of a conserved 41-to 42-amino acid residue trefoil domain with a distinctive structure, are small and secreted proteins that are co-expressed with mucins by the epithelial cells lining the gastrointestinal tract [3]. In humans, three members of the TFF have been identified and these func- 
tions are thought to center on their role in mucosal protection, namely interactions with mucins and stimulation of cell motility [4]. Because the expression of these peptides in the gut occurs in a tissue- and cell-specific manner, TFF1 and TFF2 are predominantly expressed in the gastric mucosa, with TFF1 being restricted to the foveolar epithelial cells of gastric body and antrum and TFF2 to mucous neck cells and the deep pyloric gland [3]. In contrast, TFF3 or intestinal trefoil factor (ITF) is expressed in the goblet cells of the intestine [5] and shows limited expression in the breast, salivary gland, hypothalamus, and respiratory tract outside the GI tract [6-9]. Although TFFs have been involved in the protection of the gastrointestinal tract against mucosal damage [10, 11], recent compelling evidence has emerged from experimental and clinical studies indicating a pivotal role of TFFs in the oncogenic transformation, growth, and metastatic extension of common human solid tumors [4, 6, 12-18], including gastric cancer [19, 20]. Moreover, serum levels of TFFs in patients with several cancers have been reported as useful biomarkers for predicting the presence of cancer [21-24].

In this study, we examined the expression of TFF1 and TFF3 in large series of human gastric adenocarcinomas. Next, we evaluated the association between the expression of these proteins and the clinicopathological characteristics of gastric adenocarcinomas and assessed the clinical significance of these proteins. To the best our knowledge, this study is the largest study on the expression of TFF 1 and TFF3 in gastric cancer.

\section{Materials and Methods}

\section{Study material}

A total of 292 cases of primary gastric adenocarcinoma were acquired from the Catholic University Hospital, Seoul, Korea from January 2005 to May 2010. Additional 20 cases of non-cancerous gastric mucosa were included. The study protocol was approved by the Institutional Review Board of St. Vincent's Hospital at The Catholic University of Korea (IRB No. VC12TISI0166). All of these patients had undergone a complete tumor resection. None of the patients had received preoperative chemotherapy or radiation therapy. Tumors were divided into two histological subgroups: a differentiated type consisting of papillary and tubular adenocarcinomas, and an undifferentiated type consisting of poorly differentiated adenocarcinomas, signet ring cell carcinomas, and mucinous adenocarcinomas [25]. All patients were staged at the time of their surgery, in accordance with the guidelines of the American Joint Committee on Cancer Staging system [26]. After surgery, clinical follow-up data for all patients were obtained. Survival time was measured as the time from the date of the initial surgery to the date of death. Patients that died as a result of surgery or from other causes were excluded from the study.

\section{Construction of the tissue microarray (TMA) block}

Formalin-fixed paraffin-embedded tissues were obtained from subjects. Using H\&E-stained slides, a representative tumor site was chosen and the site corresponding to the confirmed tumor site in the paraffin block was marked. Areas with necrosis, hemorrhage, and artifacts were excluded. Single core biopsy specimens of $2 \mathrm{~mm}$ in diameter were taken from the representative regions (SeongKohn Trader's Co, Seoul, Korea), placed on a TMA mold with 60 pores, and re-embedded with paraffin. TMA blocks were prepared as 4- $\mu \mathrm{m}$-thick sections and were stained with the H\&E staining methods. The tissues were then examined to determine whether the appropriate tumor site had been selected.

\section{Immunohistochemistry}

Immunohistochemical staining was conducted on $5 \mu \mathrm{m}$ sections of the tissue microarray blocks. The paraffin sections were mounted on superfrost glass slides, deparaffinized, and rehydrated in a graded series of ethanol, followed by microwave antigen retrieval. Endogeneous peroxidase activity was blocked using $0.3 \%$ hydrogen peroxide. The sections were incubated for 1 hour or overnight at $4{ }^{\circ} \mathrm{C}$ using primary antibodies at a dilution of 1:100 against TFF1 (Epitomics Inc, Burlingame,CA) and at a dilution of 1:500 against TFF3 (Abnova, Taipei, Taiwan). Immunostaining was conducted using the rabbit or mouse DAKO ChemMate ${ }^{\mathrm{TM}}$ EnVision $^{\mathrm{TM}}$ system, Peroxidase/DAB kit (DAKO, Glostrup, Denmark). The sections were then counterstained with Meyer hematoxylin and were then dehydrated, cleared, and mounted. Breast cancer was used as a positive control for TFF1 and colon cancer was used as a positive control for TFF3.

All immunostained slides were evaluated independently by two independent pathologists. Evaluation was done twice without the evaluator having any knowledge of the specific diagnosis or prognosis for each individual case. Immunohistochemical staining was re-evaluated for cases showing disagreement between pathologists. Two pathologists reviewed the cases together, and reached an agreement for samples with inconclusive results.

Tumor cells showing cytoplasm stained in 
brown under light microscopy were considered positive. Cells were scored broadly, according to the staining intensity and the percentage of positive tumor cells [27]. Staining intensity (i) were scored as follows: absence of staining, 0 point; weak staining, 1 point; moderate to strong staining, 2 points. The percentage of positive tumor cells (ii) was semiquantitatively divided into three grades: no positive staining or $<10 \%$ of tumor cells with positive staining, 0 point; $10-50 \%, 1$ point; $>50 \%, 2$ points. The score for each section was measured as (i) $\times($ ii), and the result was defined as 0 (score 0 ), $1+$ (score 1 ), $2+$ (score 2 ), and $3+$ (score 4). For statistical analysis, the expression of TFF1 was grouped into preserved (3+) and reduced $(0,1+, 2+)$ expression; the expression of TFF3 was grouped into low $(0,1+, 2+)$ and high $(3+)$ level expression.

\section{Statistical analysis}

Associations between categorical variables were analyzed using the SPSS software package, version 13.0 (SPSS Inc., Chicago, IL USA). Two-sided P values were determined via Chi-square tests. Patient's overall survival was analyzed using the Kaplan-Meier method with the use of the log-rank test for univariate analysis. The Cox proportional hazards model was used for multivariate analysis of the factors that were determined to be significant for overall survival by univariate analysis. For all analyses, the level of significance was set at $\mathrm{p}<0.05$.

\section{Results}

\section{Clinicopathological data}

Among the 292 patients studied, 186 (63.7\%) were men and $106(36.3 \%)$ were women, with a mean age of 61 years (range, 26 to 86 years). One hundred sixty-nine $(57.9 \%)$ of the studied tumors were classified as differentiated type and $123(42.1 \%)$ as undifferentiated type. The depth of invasion was T1 in 125 $(42.8 \%), \mathrm{T} 2$ in $41(14.0 \%), \mathrm{T} 3$ in 58 (19.9\%), and T4 in 68 $(23.3 \%)$ cases. There were 139 cases of gastric adenocarcinoma with a regional lymph node metastasis. In addition, there were 152 cases of lymphatic invasion, 35 cases of vascular invasion, and 101 cases of perineural invasion. One hundred thirty-four (45.9\%) cases had stage I disease, $80(27.4 \%)$ had stage II disease, and $78(26.7 \%)$ cases had stage III disease (Table 1). Follow-up data were available in all patients and the median follow-up duration was 33.3 months (range, 1.6-82.44 months) after primary surgery. Fifty-one patients died during the follow-up period, and 241 patients were alive at the time of the study.

Table I. Correlation between expression TFFI and TFF3 and clinicopathological parameters.

\begin{tabular}{|c|c|c|c|c|c|c|c|c|}
\hline \multirow[t]{2}{*}{ Variables } & & \multirow{2}{*}{$\begin{array}{l}\text { No. of } \\
\text { cases }\end{array}$} & \multicolumn{2}{|c|}{ TFF1 expression } & \multirow[t]{2}{*}{$p$ value ${ }^{*}$} & \multicolumn{2}{|c|}{ TFF3 expression } & \multirow[t]{2}{*}{$p$ value* } \\
\hline & & & preserved & reduced & & low & high & \\
\hline \multirow[t]{2}{*}{ Age (yr) } & $<60$ & 158 & $78(49.4)$ & $80(50.6)$ & 0.243 & $89(56.3)$ & $69(43.7)$ & 0.850 \\
\hline & $\geq 60$ & 134 & $57(42.5)$ & $77(57.5)$ & & $74(55.2)$ & $60(44.8)$ & \\
\hline \multirow[t]{2}{*}{ Sex } & male & 186 & $81(43.5)$ & $105(56.5)$ & 0.223 & $105(56.5)$ & $81(43.5)$ & 0.774 \\
\hline & female & 106 & $54(50.9)$ & $52(49.1)$ & & $58(54.7)$ & $48(45.3)$ & \\
\hline \multirow[t]{2}{*}{ Histologic type } & differentiated & 169 & $61(36.1)$ & $108(63.9)$ & 0.000 & $106(62.7)$ & $63(37.3)$ & 0.005 \\
\hline & undifferentiated & 123 & $74(60.2)$ & $49(39.8)$ & & $57(46.3)$ & $66(53.7)$ & \\
\hline \multirow[t]{2}{*}{ Lauren classification } & intestinal & 193 & $68(35.2)$ & $125(64.8)$ & 0.000 & $121(62.7)$ & 72(37.3) & 0.001 \\
\hline & diffuse & 99 & $67(67.7)$ & $32(32.3)$ & & $42(42.4)$ & $57(57.6)$ & \\
\hline \multirow[t]{2}{*}{ Depth of invasion } & $\mathrm{T} 1$ & 125 & $53(42.4)$ & $72(57.6)$ & 0.256 & $77(61.6)$ & $48(38.4)$ & 0.085 \\
\hline & $\mathrm{T} 2-4$ & 167 & $82(49.1)$ & $85(50.9)$ & & $86(51.5)$ & $81(48.5)$ & \\
\hline \multirow[t]{2}{*}{ Lymph node metastasis } & Absent & 153 & $67(43.8)$ & $86(56.2)$ & 0.380 & $103(67.3)$ & $50(32.7)$ & 0.000 \\
\hline & present & 139 & $68(48.9)$ & $71(51.1)$ & & $60(43.2)$ & $79(56.8)$ & \\
\hline \multirow[t]{2}{*}{ Lymphatic invasion } & Absent & 140 & $67(47.9)$ & $73(52.1)$ & 0.593 & $90(64.3)$ & $50(35.7)$ & 0.005 \\
\hline & Present & 152 & $68(44.7)$ & $84(55.3)$ & & $73(48.0)$ & $79(52.0)$ & \\
\hline \multirow[t]{2}{*}{ Vein invasion } & Absent & 257 & $119(46.3)$ & $138(53.7)$ & 0.948 & $150(58.4)$ & 107(41.6) & 0.018 \\
\hline & Present & 35 & $16(45.7)$ & $19(54.3)$ & & 13(37.1) & $22(62.9)$ & \\
\hline \multirow[t]{2}{*}{ Perineural invasion } & Absent & 191 & $81(42.4)$ & $110(57.6)$ & 0.071 & $110(57.6)$ & $81(42.4)$ & 0.402 \\
\hline & present & 101 & $54(53.5)$ & $47(46.5)$ & & $53(52.5)$ & $48(47.5)$ & \\
\hline \multirow[t]{2}{*}{ p-Stage } & I & 134 & $56(58.2)$ & $78(58.2)$ & 0.161 & $88(65.7)$ & $46(34.3)$ & 0.002 \\
\hline & II-III & 158 & $79(50.0)$ & $79(50.0)$ & & $75(47.5)$ & $83(52.5)$ & \\
\hline
\end{tabular}

Values are presented as number (\%). p-Stage, pathologic stage. ${ }^{*} \mathrm{p}<0.05$. 


\section{Expression of TFFI and TFF3}

We found TFF immunostaining in every case of normal gastric mucosa (20 cases). TFF1 expression was seen throughout the foveolar and glandular epithelium of the mucosa and the intestinal metaplastic epithelium (Fig. 1). On the other hand, TFF3 was not detected in the normal gastric foveolar epithelium. However, intestinal metaplastic epithelium was always positive and occasionally, mucosal cells in the lower half of the fundic glands were weakly positive (Fig. 1). In cancer tissues, TFF1 and TFF3 immunore-
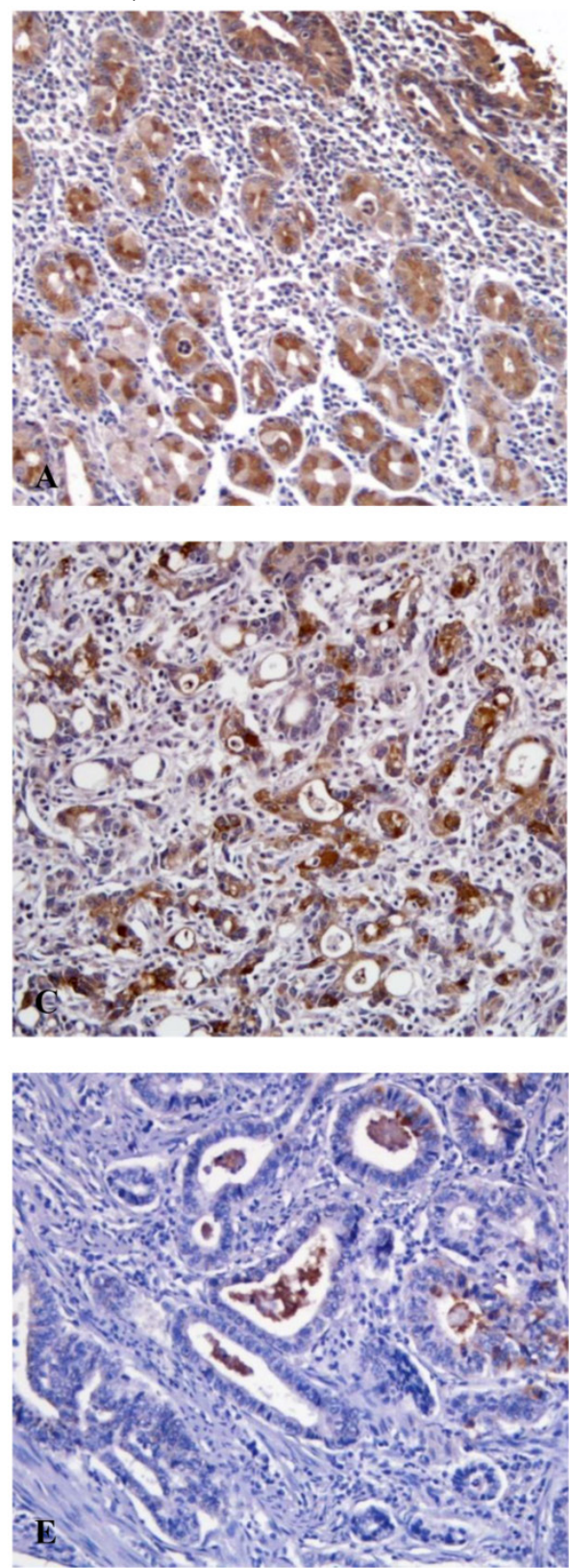

activity was found exclusively in the cytoplasm of cancer cells. Of 292 gastric adenocarcinoma cases, 135 cases $(46.2 \%)$ showed preserved TFF1 expression, but 157 cases $(53.8 \%)$ showed reduced TFF1 expression (Fig. 1). With regard to TFF3, 115 cases (39.4\%) exhibited rare TFF3 staining (0). A total of $11(3.8 \%)$, 37 $(12.7 \%)$ and $129(44.2 \%)$ cases had $1+, 2+$, and $3+$ staining for TFF3, respectively. 129 (44.2\%) tumors had a high level of expression under the classification of low $(0,1+, 2+)$ and high $(3+)$ levels of expression (Fig. 1).
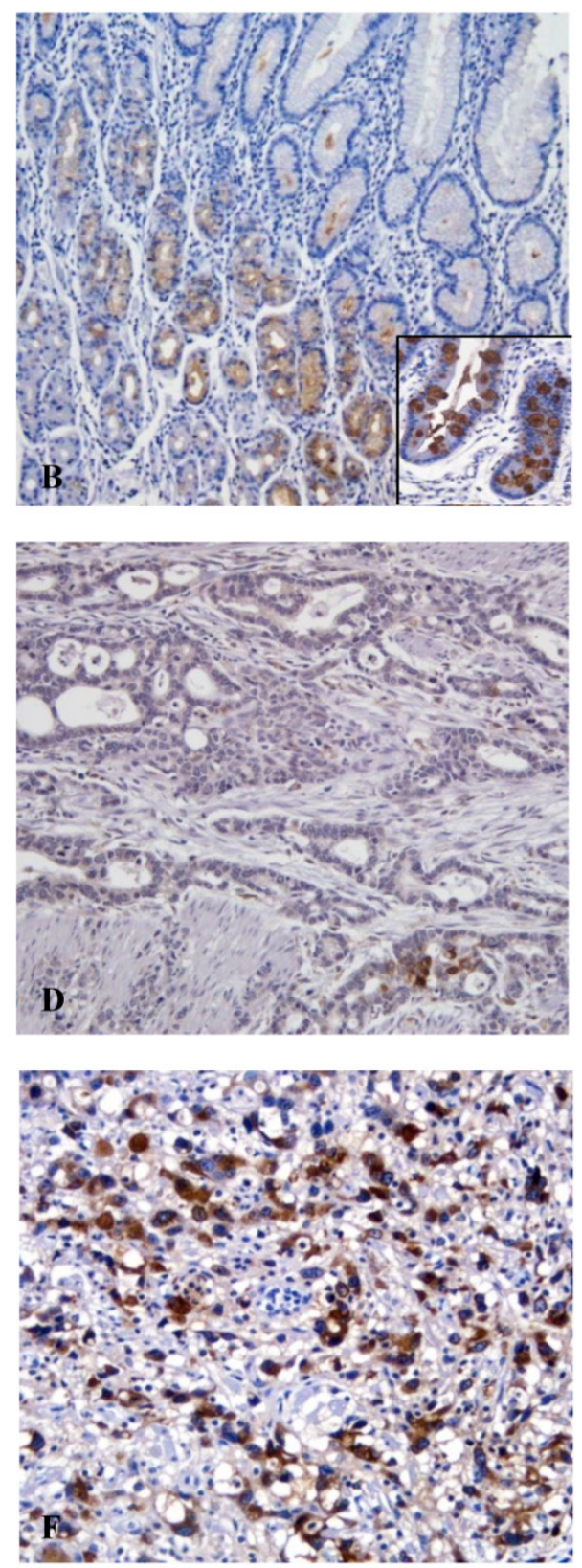

Fig. I. Immunohistochemical findings for TFFI and TFF3. (A) The normal gastric mucosa shows cytoplasmic positivity for TFFI (xI00). (B) TFF3 is not detected in normal gastric epithelial cells, however goblet cells in the intestinal metaplastic gland show strong immunoreactivity for TFF3 (inlet) (xI00). (C) Expression of TFFI is preserved in gastric cancer cells (x200). (D) The reduced expression of TFFI shows in cancer cells $(x 200)$. (E) The gastric cancer cells show low expression of TFF3 $(x 200)$. (F) TFF3 is strongly expressed in the cytoplasm of cancer cells $(x 200)$. 


\section{Relationship between the expression of TFF I and TFF3 and clinicopathological variables}

Results from the analysis of correlation between the expression of TFF1 and TFF3 and clinicopathological variables are presented in Table 1 . Regarding the histological type and the Lauren classification, TFF1 expression showed more reduced expression in cases with differentiated type $(p=0.000)$ and intestinal type $(p=0.000)$, however TFF3 expression was higher in cases with undifferentiated type $(p=0.005)$ and diffuse type $(p=0.001)$. High expression of TFF3 was significantly correlated with lymph node metastasis $(p$ $=0.000)$, lymphatic invasion $(p=0.005)$, and vein invasion $(p=0.018)$. In addition, there was a significant correlation between high expression of TFF3 and advanced stage $(p=0.002)$. However, statistically significant associations between reduced TFF1 expression and other clinicopathological variables were not identified.

\section{Survival analysis}

Survival analyses using the Kaplan-Meier method according to clinicopathological variables and expression of TFF1 and TFF3 profiles are summarized in Table 2. Depth of invasion of the tumor $(p=0.000)$, lymph node metastasis $(p=0.000)$, lymphatic invasion $(p=0.000)$, vein invasion $(p=0.000)$, perineural invasion $(p=0.000)$, and clinical stage $(p=0.000)$ demonstrated a significant correlation with overall survival (OS). Patients with high TFF3 expression had shorter OS compared to those with low TFF3 expression although survival benefits showed a statistically borderline significance $(p=0.058)$. Next, the same statistical analyses were performed according to sex and T classification. No difference was found for the expression of TFF1 and TFF3 between the two groups of sex (men and women). In patients with 125 early gastric cancers (EGCs) (T1 classification), high TFF3 expression was significantly associated with lower OS $(p=0.048)$. Moreover, when the combined expression of TFF1 and TFF3 was analyzed to evaluate its relationship with OS, patients with TFF1-reduced/TFF3-high expression had a worse prognosis than those with others $(p=0.004)$. However, in patients with advanced gastric cancer (AGC) (T2/T3/T4 classification), there was no specific correlation between the expression of TFF1 and TFF3 with OS.

Table 2. Kaplan-Meier univariate analysis of overall survival.

\begin{tabular}{|c|c|c|c|c|c|c|c|}
\hline \multirow[t]{2}{*}{ Variables } & & \multicolumn{2}{|c|}{ GC $(n=292)$} & \multicolumn{2}{|c|}{ EGC $(n=125)$} & \multicolumn{2}{|c|}{ AGC $(n=167)$} \\
\hline & & $\mathrm{n}$ & $p$ value* & $\mathrm{n}$ & $p$ value ${ }^{*}$ & $\mathrm{n}$ & $p$ value* \\
\hline \multirow[t]{2}{*}{ Age (yr) } & $<60$ & 158 & 0.137 & 70 & 0.091 & 88 & 0.484 \\
\hline & $\geq 60$ & 134 & & 55 & & 79 & \\
\hline \multirow[t]{2}{*}{ Sex } & male & 186 & 0.554 & 77 & 0.359 & 109 & 0.266 \\
\hline & female & 106 & & 48 & & 58 & \\
\hline \multirow[t]{2}{*}{ Histologic type } & differentiated & 169 & 0.905 & 81 & 0.476 & 88 & 0.771 \\
\hline & undifferentiated & 123 & & 44 & & 79 & \\
\hline \multirow[t]{2}{*}{ Lauren classification } & intestinal & 193 & 0.750 & 92 & 0.168 & 101 & 0.590 \\
\hline & diffuse & 99 & & 33 & & 66 & \\
\hline \multirow[t]{2}{*}{ Depth of invasion } & $\mathrm{T} 1$ & 125 & 0.000 & & & & \\
\hline & $\mathrm{T} 2-4$ & 167 & & & & & \\
\hline \multirow[t]{2}{*}{ Lymph node metastasis } & Absent & 153 & 0.000 & 84 & 0.004 & 69 & 0.000 \\
\hline & present & 139 & & 41 & & 98 & \\
\hline \multirow[t]{2}{*}{ Lymphatic invasion } & Absent & 140 & 0.000 & 85 & 0.009 & 55 & 0.000 \\
\hline & Present & 152 & & 40 & & 112 & \\
\hline \multirow[t]{2}{*}{ Vein invasion } & Absent & 257 & 0.010 & 120 & 0.931 & 137 & 0.000 \\
\hline & Present & 35 & & 5 & & 30 & \\
\hline \multirow[t]{2}{*}{ Perineural invasion } & Absent & 191 & 0.000 & 118 & 1.555 & 73 & 0.000 \\
\hline & present & 101 & & 7 & & 94 & \\
\hline \multirow[t]{2}{*}{ p-Stage } & I & 134 & 0.000 & 107 & 0.000 & 27 & 0.003 \\
\hline & II-III & 158 & & 18 & & 140 & \\
\hline \multirow[t]{2}{*}{ TFF1 expression } & preserved & 135 & 0.797 & 53 & 0.271 & 82 & 0.473 \\
\hline & reduced & 157 & & 72 & & 85 & \\
\hline \multirow[t]{2}{*}{ TFF3 expression } & low & 163 & 0.058 & 77 & 0.048 & 86 & 0.524 \\
\hline & high & 129 & & 48 & & 81 & \\
\hline \multirow[t]{2}{*}{ TFF1/TFF3 expression } & reduced/high & 50 & 0.692 & 20 & 0.004 & 30 & 0.175 \\
\hline & others & 242 & & 105 & & 137 & \\
\hline
\end{tabular}

GC, gastric cancer; EGC, early gastric cancer; AGC, advanced gastric cancer. $\mathrm{p}$-Stage, pathologic stage. ${ }^{*} \mathrm{p}<0.05$. 
Table 3. Cox regression multiivariate analysis of overall survival.

\begin{tabular}{|c|c|c|c|c|c|c|c|}
\hline \multirow[t]{2}{*}{ Variables } & & \multicolumn{3}{|c|}{$\mathrm{GC}(\mathrm{n}=292)$} & \multicolumn{3}{|c|}{$\mathrm{EGC}(\mathrm{n}=125)$} \\
\hline & & $\overline{\mathrm{HR}}$ & $95 \% \mathrm{CI}$ & $p$-value* & HR & $95 \% \mathrm{CI}$ & $p$-value ${ }^{*}$ \\
\hline Depth of invasion & T1 vs T2-4 & 0.754 & $0.340-1.670$ & 0.486 & & & \\
\hline Lymph node metastasis & absent vs present & 3.889 & $1.603-9.435$ & 0.003 & 0.403 & $0.026-6.342$ & 0.518 \\
\hline Lymphatic invasion & absent vs present & 1.418 & $0.439-4.580$ & 0.560 & 1.125 & $0.156-8.126$ & 0.983 \\
\hline Vein invasion & absent vs present & 1.523 & $0.818-2.836$ & 0.184 & 0.310 & $0.023-4.094$ & 0.373 \\
\hline Perineural invasion & absent vs present & 1.872 & $1.003-3.493$ & 0.049 & 1.705 & $0.356-8.152$ & 0.504 \\
\hline p-Stage & I vs II-III & 6.655 & $1.879-23.573$ & 0.003 & 14.212 & $3.801-53.131$ & 0.000 \\
\hline TFF3 expression & low vs high & 1.171 & $0.662-2.072$ & 0.587 & 1.020 & $0.168-6.183$ & 0.983 \\
\hline TFF1/TFF3 expression & reduced/high vs others & 1.047 & $0.478-2.293$ & 0.908 & 4.170 & $1,283-13.550$ & 0.018 \\
\hline
\end{tabular}

GC, gastric cancer; EGC, early gastric cancer. HR, hazard ration; CI, confidence interval; p-Stage, pathologic stage. * $\mathrm{p}<0.05$.

Multivariate analysis using the Cox proportional hazard model was performed to evaluate independent prognostic predictors in patients with GC. As shown in Table 3, the independent prognostic factors that were significantly associated with OS in patients with 292 GCs were stage $(p=0.003)$, lymph node metastasis $(p=0.003)$, and perineural invasion $(p=0.049)$. In patients with 125 EGCs, stage proved to be an independent prognostic factor for OS $(p=0.000)$. In addition, a combination of reduced TFF1 expression and high TFF3 expression $(p=0.018)$ was determined as an independent prognostic factor significantly associated with poor OS in patients with EGC.

\section{Discussion}

In this study, we determined the expression of TFF1 and TFF3 in a large series of human gastric adenocarcinomas and hoped to achieve a more precise understanding of the associations of these protein expressions with clinicopathological characteristics including patient survival.

TFF1 or pS2 was first identified by virtue of its regulation by estrogen in breast cancer cells [28] and is expressed in a variety of carcinomas including breast cancer $[12,29-31]$. With regard to gastric carcinogenesis, TFF1 knockout mice develop gastric adenomas and carcinomas [32], and TFF1 is markedly down-regulated in human gastric cancer $[19,20,33$, 34], suggesting that TFF1 is a tumor suppressor for human gastric cancer. In our study, we found that normal gastric tissues expressed TFF1 in all cases, however, $53.8 \%$ of gastric cancers showed reduced TFF1 expression, a frequency that is close to previous reports $[33,35,36]$.

Interestingly, we observed a significantly higher frequency of TFF1 expression in cases with undifferentiated type and diffuse type than in those with differentiated type and intestinal type, respectively, which is consistent with the results obtained by Ma- chado et al [34] and Wu et al [36] and in contrast with those of Muller et al [33] who did not find any significant relationship between TFF1 expression and the histological type of gastric cancer. As for the histogenesis of gastric cancer, it has generally been concluded that differentiated type (intestinal type) carcinomas arise from areas of intestinal metaplasia, whereas undifferentiated (diffuse type) lesions originate from normal gastric mucosa [25]. Muller et al [33] found a highly significant correlation between TFF1 expression and pepsinogen II, a marker of gastric differentiation. In addition, evidence provided by an ultrastructural study showed that gastric-type cells were observed in the majority of diffuse carcinomas [37]. However, contrary to this hypothesis, Yoshikawa et al [38] reported a high incidence of differentiated type gastric cancers showed gastric phenotypic markers. Moreover, Fiocca et al [39] reported gastric type differentiation in $55 \%$ of differentiated type gastric carcinomas. Therefore, a higher frequency of TFF1 expression in cases with undifferentiated type and diffuse type than in those with differentiated type and intestinal type may suggest two assumptions. First, this finding may represent that TFF1 expression discloses the gastric phenotype of neoplastic cells. Second, if regardless of histogenesis, loss of TFF1 may be involved in the development of more differentiated gastric cancer [36].

Regarding the association between TFF1 expression and clinicopathological features, we found no statistically significant associations between a variety of clinicopathological indicators for poor prognosis and patient survival. Similar to our results, Muller et al [33], Machado et al [34], and Wu et al [36] found the lack of correlation between TFF1 expression and patient survival. However, Suarez et al [40] reported that high intratumoral TFF1 levels were significantly associated with unfavorable outcome. Therefore, further studies are warranted to examine the clinical signifi- 
cance of TFF1 and its usefulness as a prognostic marker.

TFF3 is upregulated in most human malignancies including primary gastric cancer [6, 18-21, 24]. Moreover, its expression is correlated with a highly aggressive phenotype and poor prognosis $[16,21,24$, 27]. Previous studies from several researchers have reported that the oncogenic potential of TFF3 is attributed to cell proliferation [41], inhibition of cell adhesion [17], blocking apoptosis [14, 42], invasion [13], and angiogenesis [15, 43]. In the present study, we found that $60.6 \%$ of gastric cancer expressed TFF3, which is consistent with previous reports $[20,25]$. We also found high TFF3 expression in cases with undifferentiated type and diffuse type. According to histogenesis in gastric cancer, high TFF3 expression is expected in gastric cancers with differentiated type and intestinal type, because TFF3 is strongly expressed by the goblet cells in the normal intestine and in the intestinal metaplastic epithelium of the stomach, which was shown in previous studies as well as our present study [25]. However, our study showed an opposite result, which may show that undifferentiated type (diffuse type) carcinomas arise mainly from the normal gastric mucosa and the change from gastric to intestinal phenotype occurs with time [25, 38].

Concerning the clinical significance of TFF3 expression, we found that high TFF3 expression was significantly correlated with lymph node metastasis, lymphatic invasion, vein invasion, and advanced stage. Additionally, we demonstrated that patients with high expression of TFF3 had a lower survival rate than those with low expression of TFF3 by univariate analysis. Only a few data have been reported regarding the correlation between TTF3 expression and clinicopathological features in gastric cancer [15, 25, 27]. Yamachika et al [25] revealed TFF3 positivity to be an independent predictor of poor prognosis. More specially, they found men and women had different TFF3 expression levels; higher expression of TFF3 in women with gastric cancer and expression of TFF3 in men correlated with the aggressive phenotype of tumors. However, Dhar et al [15] reported that TFF3 expression did not have a significant impact on overall survival. Instead, TFF3 overexpression had a significant impact on overall survival only in female patients. In the present study, when survival analysis was repeated separately for male and female patients, high expression of TFF3 did not demonstrate a significant prognostic impact (data not shown). Recently, Meng et al [27] described that TFF 3 positive expression had a significant relationship with a lower survival rate in comparison to that of negative expres- sion, but they did not perform multivariate analysis. These results including our data suggest that TFF3 may play an important role in promoting gastric cancer development, progression and dissemination.

Early gastric cancer (EGC) is defined as GC confined to the mucosa and/or submucosa irrespective of lymph node metastasis, according to the Japanese Classification of Gastric Carcinom (JCGC) [44]. In spite of the very favorable prognosis of EGC, recurrence and second primary cancers are present in certain patients after curative surgery. Therefore, studies on prognostic factors in EGC enable us to provide a more tailored follow-up schedule and treatment for high-risk patients. In accordance with this point of view, when we analyzed the association between TFF3 expression and patient survival in patients with EGC, we found that patients with high expression of TFF3 had a lower survival rate than those with low expression of TFF3 by univariate analysis, although it lost significance in multivariate analysis. Next, we also analyzed the relationship between the combined expression of TFF1 and TFF3 and overall survival because researchers had shown that induction of TFF3 together with the progressive loss of TFF1 and TFF 2 is possibly involved in the early stage of the multi-step gastric cancer pathway [20]. Interestingly, we found that the combination of reduced TFF1 expression and high TFF3 expression is an independent poor prognostic factor in patients with EGC, which is a remarkable result in our study. This suggests that high TFF3 expression may play a role in tumor progression associated with reduced TFF1 expression in patients with EGC.

In conclusion, reduced expression of TFF1 and increased expression of TFF3 may play a role in the carcinogenesis of gastric cancer and high expression of TFF3 may contribute to tumor progression. Moreover, we suggest the high expression of TFF3, which is associated with reduced expression of TFF1, may be a marker of poor prognosis for patients with EGC. These findings warrant additional molecular and clinicopathological studies of those markers and their related pathways that are potentially relevant to the prognosis of gastric cancer.

\section{Acknowledgement}

This study was supported by the 2011 Research Grants from St. Vincent's Hospital.

\section{Competing Interests}

The authors have declared that no competing interest exists. 


\section{References}

1. Parkin DM, Bray F, Ferlay J, Pisani P. Global cancer statistics, 2002. CA Cancer J Clin. 2005; 55: 74-108.

2. Macdonald JS, Smalley SR, Benedetti J, Hundahl SA, Estes NC, Stemmermann GN, et al. Chemoradiotherapy after surgery compared with surgery alone for adenocarcinoma of the stomach or gastroesophageal junction. N Engl J Med. 2001; 345: 725-30.

3. Wright NA, Poulsom R, Stamp G, Van Noorden S, Sarraf C, Elia G, et al. Trefoil peptide gene expression in gastrointestinal epithelial cells in inflammatory bowel disease. Gastroenterology. 1993; 104: 12-20.

4. May FE, Westley BR. Trefoil proteins: their role in normal and malignant cells. J Pathol. 1997; 183: 4-7.

5. Podolsky DK, Lynch-Devaney K, Stow JL, Oates P, Murgue B, DeBeaumont $\mathrm{M}$, et al. Identification of human intestinal trefoil factor. Goblet cell-specific expression of a peptide targeted for apical secretion. J Biol Chem. 1993; 268: 6694-702.

6. Poulsom R, Hanby AM, Lalani EN, Hauser F, Hoffmann W, Stamp GW. Intestinal trefoil factor (TFF 3) and pS2 (TFF 1), but not spasmolytic polypeptide (TFF 2) mRNAs are co-expressed in normal, hyperplastic, and neoplastic human breast epithelium. J Pathol. 1997; 183: 30-8.

7. Devine DA, High AS, Owen PJ, Poulsom R, Bonass WA. Trefoil factor expression in normal and diseased human salivary glands. Hum Pathol. 2000; 31: 509-15.

8. Jagla W, Wiede A, Dietzmann K, Rutkowski K, Hoffmann W. Co-localization of TFF3 peptide and oxytocin in the human hypothalamus. FASEB J. 2000; 14: 1126-31.

9. dos Santos Silva E, Ulrich M, Doring G, Botzenhart K, Gott P. Trefoil factor family domain peptides in the human respiratory tract. J Pathol. 2000; 190: 133-42.

10. Taupin D, Podolsky DK. Trefoil factors: initiators of mucosal healing. Nat Rev Mol Cell Biol. 2003; 4: 721-32.

11. Hernandez C, Santamatilde E, McCreath KJ, Cervera AM, Diez I, Ortiz-Masia D, et al. Induction of trefoil factor (TFF)1, TFF2 and TFF3 by hypoxia is mediated by hypoxia inducible factor-1: implications for gastric mucosal healing. Br J Pharmacol. 2009; 156: 262-72.

12. Henry JA, Bennett MK, Piggott NH, Levett DL, May FE, Westley BR. Expression of the pNR-2/pS2 protein in diverse human epithelial tumours. Br J Cancer. 1991; 64: 677-82.

13. Chan VY, Chan MW, Leung WK, Leung PS, Sung JJ, Chan FK. Intestinal trefoil factor promotes invasion in non-tumorigenic Rat-2 fibroblast cell. Regul Pept. 2005; 127: 87-94.

14. Yio X, Zhang JY, Babyatsky M, Chen A, Lin J, Fan QX, et al. Trefoil factor family- 3 is associated with aggressive behavior of colon cancer cells. Clin Exp Metastasis. 2005; 22: 157-65.

15. Dhar DK, Wang TC, Tabara H, Tonomoto $Y$, Maruyama R, Tachibana M, et al. Expression of trefoil factor family members correlates with patient prognosis and neoangiogenesis. Clin Cancer Res. 2005; 11: 6472-8.

16. Babyatsky M, Lin J, Yio X, Chen A, Zhang JY, Zheng Y, et al. Trefoil factor-3 expression in human colon cancer liver metastasis. Clin Exp Metastasis. 2009; 26: 143-51.

17. Efstathiou JA, Noda M, Rowan A, Dixon C, Chinery R, Jawhari A, et al. Intestinal trefoil factor controls the expression of the adenomatous polyposis coli-catenin and the E-cadherin-catenin complexes in human colon carcinoma cells. Proc Natl Acad Sci U S A. 1998; 95: 3122-7.

18. Taupin D, Ooi K, Yeomans N, Giraud A. Conserved expression of intestinal trefoil factor in the human colonic adenoma-carcinoma sequence. Lab Invest. 1996; 75: 25-32.

19. Kirikoshi $\mathrm{H}$, Katoh M. Expression of TFF1, TFF2 and TFF3 in gastric cancer. Int J Oncol. 2002; 21: 655-9.

20. Leung WK, Yu J, Chan FK, To KF, Chan MW, Ebert MP, et al. Expression of trefoil peptides (TFF1, TFF2, and TFF3) in gastric carcinomas, intestinal metaplasia, and non-neoplastic gastric tissues. J Pathol. 2002; 197: 582-8.

21. Vestergaard EM, Borre M, Poulsen SS, Nexo E, Torring N. Plasma levels of trefoil factors are increased in patients with advanced prostate cancer. Clin Cancer Res. 2006; 12: 807-12.

22. Kaise M, Miwa J, Tashiro J, Ohmoto Y, Morimoto S, Kato M, et al. The combination of serum trefoil factor 3 and pepsinogen testing is a valid non-endoscopic biomarker for predicting the presence of gastric cancer: a new marker for gastric cancer risk. J Gastroenterol. 2011; 46: 736-45.

23. Aikou S, Ohmoto Y, Gunji T, Matsuhashi N, Ohtsu H, Miura H, et al. Tests for serum levels of trefoil factor family proteins can improve gastric cancer screening. Gastroenterology. 2011; 141: 837-45.

24. Qu Y, Yang Y, Ma D, Xiao W. Increased trefoil factor 3 levels in the serum of patients with three major histological subtypes of lung cancer. Oncol Rep. 2012; 27: 1277-83.
25. Yamachika T, Werther JL, Bodian C, Babyatsky M, Tatematsu M, Yamamura Y, et al. Intestinal trefoil factor: a marker of poor prognosis in gastric carcinoma. Clin Cancer Res. 2002; 8: 1092-9.

26. Washington K. 7th edition of the AJCC cancer staging manual: stomach. Ann Surg Oncol. 2010; 17: 3077-9.

27. Meng JR, Tang HZ, Zhou KZ, Shen WH, Guo HY. TFF3 and survivin expressions associate with a lower survival rate in gastric cancer. Clin Exp Med. 2012.

28. Masiakowski P, Breathnach R, Bloch J, Gannon F, Krust A, Chambon P. Cloning of cDNA sequences of hormone-regulated genes from the MCF-7 human breast cancer cell line. Nucleic Acids Res. 1982; 10: 7895-903.

29. Henry JA, Piggott NH, Mallick UK, Nicholson S, Farndon JR, Westley $\mathrm{BR}$, et al. pNR-2/pS2 immunohistochemical staining in breast cancer: correlation with prognostic factors and endocrine response. Br J Cancer. 1991; 63: 615-22.

30. Kosriwong K, Menheniott TR, Giraud AS, Jearanaikoon P, Sripa B, Limpaiboon T. Trefoil factors: tumor progression markers and mitogens via EGFR/MAPK activation in cholangiocarcinoma. World J Gastroenterol. 2011; 17: 1631-41.

31. Weise A, Dunker N. High trefoil factor 1 (TFF1) expression in human retinoblastoma cells correlates with low growth kinetics, increased cyclin-dependent kinase (CDK) inhibitor levels and a selective down-regulation of CDK6. Histochem Cell Biol. 2012.

32. Lefebvre O, Chenard MP, Masson R, Linares J, Dierich A, LeMeur M, et al. Gastric mucosa abnormalities and tumorigenesis in mice lacking the pS2 trefoil protein. Science. 1996; 274: 259-62.

33. Muller W, Borchard F. pS2 protein in gastric carcinoma and normal gastric mucosa: association with clincopathological parameters and patient survival. J Pathol. 1993; 171: 263-9.

34. Machado JC, Carneiro F, Ribeiro P, Blin N, Sobrinho-Simoes M. pS2 protein expression in gastric carcinoma. An immunohistochemical and immunoradiometric study. Eur J Cancer. 1996; 32A: 1585-90.

35. Luqmani Y, Bennett C, Paterson I, Corbishley CM, Rio MC, Chambon P, et al. Expression of the pS2 gene in normal, benign and neoplastic human stomach. Int J Cancer. 1989; 44: 806-12.

36. Wu MS, Shun CT, Wang HP, Lee WJ, Wang TH, Lin JT. Loss of pS2 protein expression is an early event of intestinal-type gastric cancer. Jpn J Cancer Res. 1998; 89: 278-82.

37. Fiocca R, Villani L, Tenti P, Solcia E, Cornaggia M, Frigerio B, et al. Characterization of four main cell types in gastric cancer: foveolar, mucopeptic, intestinal columnar and goblet cells. An histopathologic, histochemical and ultrastructural study of "early" and "advanced" tumours. Pathol Res Pract. 1987; 182: 308-25.

38. Yoshikawa A, Inada Ki K, Yamachika T, Shimizu N, Kaminishi M, Tatematsu M. Phenotypic shift in human differentiated gastric cancers from gastric to intestinal epithelial cell type during disease progression. Gastric Cancer. 1998; 1: 134-41.

39. Fiocca R, Cornaggia M, Villani L, Capella C, Solcia E, Samloff IM. Expression of pepsinogen II in gastric cancer. Its relationship to local invasion and lymph node metastases. Cancer. 1988; 61: 956-62.

40. Suarez C, Vizoso F, Rodriguez JC, Garcia I, Raigoso P, Allende MT, et al. Prognostic significance of cytosolic pS2 protein content in gastric cancer. Int J Biol Markers. 2001; 16: 37-44.

41. Chan MW, Chan VY, Leung WK, Chan KK, To KF, Sung JJ, et al. Anti-sense trefoil factor family-3 (intestinal trefoil factor) inhibits cell growth and induces chemosensitivity to adriamycin in human gastric cancer cells. Life Sci. 2005; 76: 2581-92.

42. Taupin DR, Kinoshita K, Podolsky DK. Intestinal trefoil factor confers colonic epithelial resistance to apoptosis. Proc Natl Acad Sci U S A. 2000; 97: 799-804.

43. Rodrigues S, Van Aken E, Van Bocxlaer S, Attoub S, Nguyen QD, Bruyneel E, et al. Trefoil peptides as proangiogenic factors in vivo and in vitro: implication of cyclooxygenase-2 and EGF receptor signaling. FASEB J. 2003; 17: 7-16.

44. Japanese Gastric Cancer A. Japanese Classification of Gastric Carcinoma -2nd English Edition. Gastric Cancer. 1998; 1: 10-24. 